04

\title{
Распределение заряженных частиц вблизи фронта ударной волны в тлеющем разряде
}

\author{
(C) А.С. Барышников, ${ }^{1}$ И.В. Басаргин, ${ }^{1}$ Н.О. Безверхний, ${ }^{2}$ C.В. Бобашев, ${ }^{1,2}$ Н.А. Монахов, ${ }^{1}$ \\ П.А. Попов, ${ }^{1}$ В.А. Сахаров, ${ }^{1}$ М.В. Чистякова ${ }^{1}$ \\ ${ }^{1}$ Физико-технический институт им. А.Ф. Иоффре РАН, \\ 194021 Санкт-Петербург, Россия \\ ${ }^{2}$ Санкт-Петербургский государственный университет Петра Великого, \\ 195251 Санкт-Петербург, Россия \\ e-mail: nm1988@mail.ru
}

(Поступило в Редакцию 24 апреля 2017 г.)

Измерено распределение заряженных частиц по обе стороны фронта ударной волны при ее движении в плазме тлеющего разряда. Обнаружено, что перед фронтом ударной волны концентрация ионов изменяется немонотонно. За фронтом ударной волны концентрация заряженных частиц изменяется плавно в отличие от плотности нейтральной компоненты.

DOI: 10.21883/JTF.2018.02.45404.2300

Проблема взаимодействия ударной волны с низкотемпературной плазмой газового разряда активно исследуется в течение многих лет [1-3]. В этих работах, в частности, было обнаружено изменение структуры фронта ударной волны в плазме тлеющего разряда. В работах [2,3] наблюдалось изменение проводимости плазмы перед ударной волной. В более поздних работах $[4,5]$ этот эффект был подтвержден и было показано, что это изменение происходит одновременно во всем объеме разряда. Настоящая работа является продолжением начатых исследований, направленных на изучение физического механизма наблюдаемого явления.

Эксперименты проводились на плазмогазодинамической установке, рабочая камера которой имеет диаметр $300 \mathrm{~mm}$ и высоту $400 \mathrm{~mm}$. В камере в атмосфере воздуха при давлении $4 \mathrm{kPa}$ создается стационарный газовый разряд между двумя коническими электродами, расположенными вертикально на расстоянии $100 \mathrm{~mm}$ друг от друга. Катод и рабочая камера заземлены и подключены к отрицательному полюсу источника напряжения. Анод подключен к положительному полюсу источника, который обеспечивает ток разряда $1.1 \mathrm{~A}$ при напряжении на электродах $680 \mathrm{~V}$. Разряд имеет форму тела вращения с увеличивающимся поперечным сечением по направлению к катоду. Особенностью данной экспериментальной установки является то, что в ней разряд реализуется в свободном пространстве вдали от стенок камеры. Диаметр сечения видимой части разряда составляет менее $1 / 3$ диаметра рабочей камеры. Температура окружающего разряд газа оставалась близкой к комнатной благодаря системе водяного охлаждения электродов и стенок рабочей камеры.

Ударная волна формируется в электроразрядной ударной трубе с внутренним диаметром $30 \mathrm{~mm}$ и длиной $700 \mathrm{~mm}$. Ось трубы перпендикулярна оси разряда и проходит посередине разрядного промежутка. Напротив ударной трубы соосно с ней находится электрический зонд, который может перемещаться в горизонтальном направлении. Отсчет пространственной координаты ведется от центра разряда по направлению движения ударной волны. Выходное сечение ударной трубы находится на расстоянии $100 \mathrm{~mm}$ от оси разряда. Поскольку труба является частью внутреннего пространства рабочей камеры, то начальные параметры, при которых формируется ударная волна, равны параметрам газа в рабочей камере. Скорость ударной волны на выходе трубы составляет $1200 \mathrm{~m} / \mathrm{s}$, что соответствует значениям числа Маха 3.6. Температура нейтральной компоненты (температура газа) составляет $\sim 1200 \mathrm{~K}$, электронов $\sim 12000 \mathrm{~K}$, степень ионизации не более $10^{-6}$.

Для синхронизации системы регистрации и определения положения ударной волны в настоящем исследовании использовались две шлирен-системы. В качестве источника света применялись полупроводниковые лазеры с диаметром светового луча не более $5 \mathrm{~mm}$. Приемником излучения является фотодиод с ножом Фуко, расположенный на расстоянии двух метров от объекта исследования. Это позволяет обеспечивать достаточную чувствительность оптической системы при отклонении луча ударной волной. Одна оптическая система оставалась неподвижной и располагалась между выходом ударной трубы и осью разряда на расстоянии $60 \mathrm{~mm}$ от последней. Электрический сигнал этой системы использовался для синхронизации измерений. Луч другой оптической системы всегда проходит через точку расположения электрического зонда, и ее сигнал определяет момент прихода ударной волны в точку измерения.

Локальные параметры плазмы измерялись двойным электрическим зондом, представляющим собой два параллельных платиновых электрода диаметром $0.5 \mathrm{~mm}$ и длиной $10 \mathrm{~mm}$, разнесенных в горизонтальной плоскости на расстояние $8 \mathrm{~mm}$. Электроды зонда ориентированы параллельно оси разряда. Между электродами приложе- 


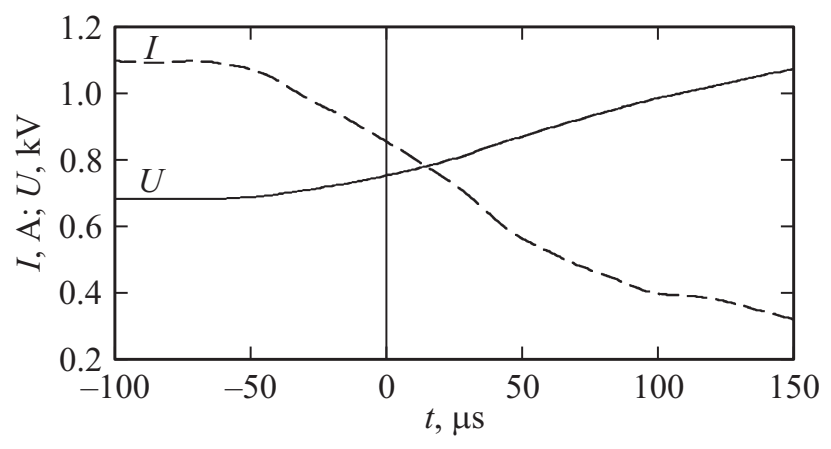

Рис. 1. Изменение тока разряда $I$ и напряжения $U$ на разрядном промежутке при взаимодействии ударной волны с газовым разрядом.

но постоянное напряжение величиной $40 \mathrm{~V}$, что обеспечивает работу двойного зонда в режиме насыщения ионного тока. Ток зонда в этом случае пропорционален произведению концентрации ионов и квадратному корню из температуры электронов.

Для контроля изменения газодинамических параметров течения за ударной волной использовался пьезоэлектрический датчик давления, который устанавливается вместо электрического зонда. В целях защиты от высокой температуры датчик располагался вне разряда, а динамическая нагрузка передавалась чувствительному элементу через кварцевый стержень длиной $0.5 \mathrm{~m}$ и диаметром $4 \mathrm{~mm}$. Один торец стержня соединен с чувствительным элементом датчика, другой располагался в точке измерения.

При прохождении ударной волны через разряд измерялись интегральные электрические параметры газового разряда. На рис. 1 показано изменение тока $I$ и напряжения $U$ на электродах разрядного промежутка при прохождении ударной волны через разряд. Здесь и далее момент времени $t=0$ соответствует приходу ударной волны к оси разряда. На графиках видно, что изменение разрядного тока и напряжения на электродах разрядного промежутка начинаются при $t=-70 \mu \mathrm{s}$. Это соответствует положению ударной волны на расстоянии примерно $80 \mathrm{~mm}$ от центра разряда, т.е. практически сразу на выходе из канала ударной трубы. Из рисунка видно, что к моменту прихода ударной волны к оси разряда ток уменьшается на 20\%, а напряжение увеличивается на $10 \%$ от начального уровня.

В разряде ударная волна движется по пространству с неоднородными параметрами. Число Маха ударной волны внутри разряда, как показали измерения, не превосходит 1.5. На рис. 2 показан сигнал датчика полного давления, расположенного на оси разряда. Сигнал датчика давления отражает изменение статического давления и скоростного напора на фронте ударной волны. Величина полного давления нормирована на значение начального давления в рабочей камере. На рисунке видно, что на фронте ударной волны наблюдается ступенчатое увеличение полного давления. Наблюдаемые за фронтом колебания сигнала вызваны возбуждением собственных колебаний чувствительного элемента датчика давления и измерительной системы. По измеренной скорости ударной волны было рассчитано увеличение плотности газа на фронте волны, которое не превышало 2. Характерное время изменения газодинамических параметров на фронте ударной волны, определенное по сигналу датчика полного давления, не превышает $5 \mu \mathrm{s}$.

Поскольку к моменту прихода ударной волны в центр разряда напряжение в разрядном промежутке увеличилось не более чем на $10 \%$ (см. рис. 1), можно предположить, что при движении ударной волны в разряде температура электронов остается постоянной. Поэтому можно считать, что отношение тока зонда к его значению в стационарном разряде равно относительному изменению концентрации ионов. На рис. 3 сплошной кривой показано относительное изменение концентрации ионов на оси разряда при движении по нему ударной волны. Погрешность измерений относительной концентрации,

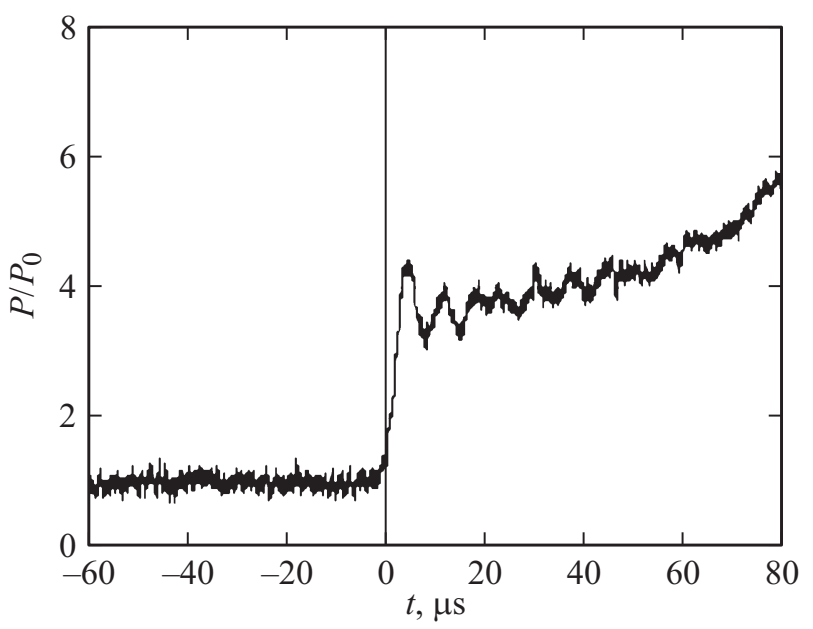

Рис. 2. Изменение полного давления газа в тлеющем разряде в окрестности фронта ударной волны.

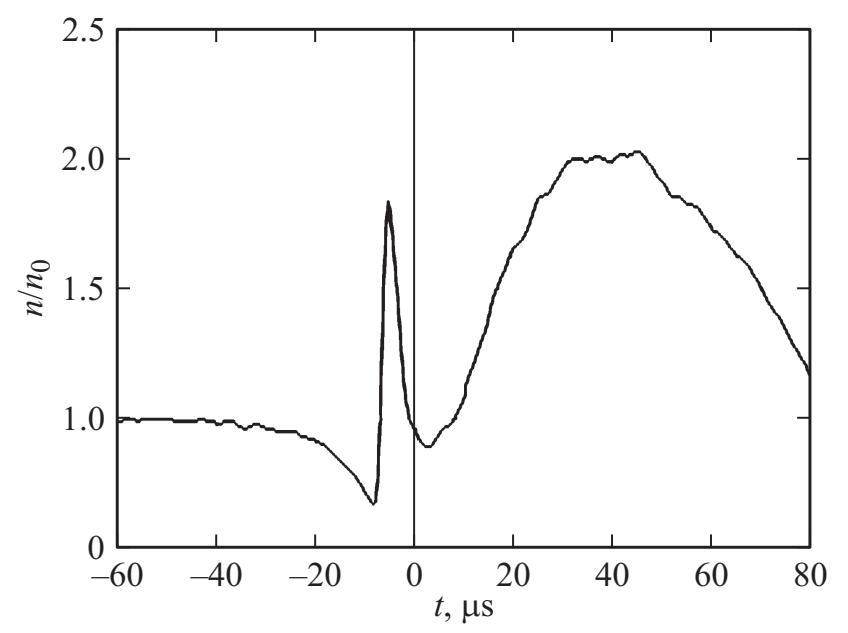

Рис. 3. Изменение относительной концентрации ионов в тлеющем разряде в окрестности фронта ударной волны. 
как показывают оценки, не превышает 10\%. На рисунке видно, что начальный уровень относительной концентрации начинает уменьшаться примерно при $t=-50 \mu \mathrm{s}$, достигая величины 0.7 от начального уровня. Затем при $t=-10 \mu \mathrm{s}$ монотонное уменьшение концентрации сменяется сравнительно коротким ее увеличением до локального максимума при $t=-5 \mu \mathrm{s}$.

К моменту прихода ударной волны относительная концентрация уменьшается практически до исходного уровня и за фронтом ударной волны, как видно из рисунка, вновь возрастает, достигая локального максимума через $50 \mu \mathrm{s}$ после прохождения ударной волны. Заметим, что относительная концентрация ионов в максимуме увеличивается примерно вдвое, что соответствует увеличению относительной плотности газа за фронтом ударной волны.

В результате исследования показано, что перед фронтом ударной волны в неравновесной плазме наблюдается немонотонное изменение концентрации ионов со значительными по величине локальными экстремумами, тогда как за фронтом ударной волны плотности ионов изменяются плавно в отличие от изменения плотности нейтральной компоненты.

Физический механизм, определяющий сложный характер изменения концентрации ионов в окрестности фронта ударной волны, возможно, связан с неравновесным состоянием плазмы тлеющего разряда и требует дальнейшего исследования.

Работа поддержана грантом РФФИ № 15-08-06280.

\section{Список литературы}

[1] Чутов Ю.И. // ПМТФ. 1970. № 1. С. 124-130.

[2] Басаргин И.В., Мишин Г.И. // Письма в ЖТФ. 1985. Т. 11. Вып. 4. С. 209-215.

[3] Горшков В.А., Климов А.И., Коблов А.Н., Мишин Г.И., Федотов К.В., Явор И.П. // ЖТФ. 1987. Т. 57. Вып. 10. C. $1893-1898$.

[4] Барышников А.С., Басаргин И.В., Бобашев С.В., Монахов Н.А., Попов П.А., Сахаров В.А., Чистякова М.В. // Письма в ЖТФ. 2015. Т. 41. Вып. 15. С. 83-89.

[5] Барышников А.С., Басаргин И.В., Бобашев С.В., Монахов Н.А., Попов П.А., Сахаров В.А., Чистякова М.В. // ИФЖ. 2016. Т. 89. № 3. С. 555-558. 